\title{
The performance of children and adolescents with low vision on the Pediatric Balance Scale
}

\author{
Agda Cristina de Sousa Santos ${ }^{1 *}$, Hanne Alves Bakke ${ }^{1}$, Ilana Santos de Oliveira ${ }^{1}$, Silvia \\ Warnick Sarinho ${ }^{1}$
}

ORIGINAL ARTICLE

\begin{abstract}
The aim of this study was to investigate the performance of children and adolescents with low vision on the Pediatric Balance Scale (PBS), in different age groups. The PBS was administered to 41 subjects, aged 5 to 14 years, with low vision and no other associated disorders. The Spearman correlation coefficient was used for correlation between age and the score achieved on the scale. There was a correlation of 0.52 between the score obtained on the PBS and the age. The variation of score was greater in children between 5 to 7 years and minimal in older age groups. The maximum score was obtained by all the subjects on six items of the scale. The PBS score had significant correlation with age up to a point, reaching ceiling effect on various items. It showed to be an easy application screening tool in children and adolescents with low vision, being more suitable for children 5-7 years old.

Keywords: visual disorders, child development, balance, low vision.
\end{abstract}

\section{INTRODUCTION}

Balance can be defined as the ability to keep the same posture, when it is placed in different positions or even to perform a specific task; and the ability to maintain the center of mass within the confines of the support base; called "the limits of stability". These limits are not fixed and change in accordance with the task to be performed, the individual biomechanics and environmental demand (Eckert, 1993).

The visual, vestibular and somatosensory systems are the main sources of sensory information necessary for the operation of maintaining balance. There is a predominance of the visual over the other sensory systems, and humans tend to use and rely primarily on vision for many functions requiring coordinated control for them to be provided the most relevant information on the environment (Soares, Gomes, \& Pereira, 2012; Gallahue, Ozmun, \& Goodway, 2013). Several studies relate changes in the equilibrium function with visual impairment (Andrade, Costa Gois, \& Victorio Vitor, 2012; Aydog, Aydog, \& Cakci, Doral, 2006; Bortolaia, Barela, \& Barela, 2003; Matos, Matos, \& Oliveira, 2010; Navarro, Fukujima, Fontes, Matas, \&
Prado, 2004), which tends to become insufficient in this situation.

The posture control and balance skills vary between the levels of age due to the maturation systems that contribute to posture control (Butz, Sweeney, Roberts, \& Rauh, 2015). There is a transition from immature to mature equilibrium responses between the ages of 4 and 10 years. There is a sequence for balance skill to appear. At twelve months of age the child is able to stay alone standing and maintain a stable posture in the standing position, but still with a broad support base and with little stability, even for walking. The activity of balancing on one foot at a time for 3-5 seconds occurs from the age of five years old. Axial movements (slope, spins and rotations) around six years old (Gallahue, Ozmun, \& Goodway, 2013). Several studies report that the development of balance in children with visual impairment is established later (Bortolaia et al., 2003; Malta, Endriss, Rache, Moura, \& Ventura, 2006; Matos, \& Oliveira, 2010; Navarro et al., 2004).

Visual impairment is a limiting factor for the development process as a whole. Therefore, losing sight early on, or being born without it,

\footnotetext{
Manuscript received at January 10 $0^{\text {th }} 2018$; Accepted at August $16^{\text {th }} 2018$

${ }^{1}$ Federal Universidad of Pernambuco, Recife, Pernambuco, Brazil

*Corresponding author: agdacriss@gmail.com
} 
can result in the impairment of basic activities related to movement, such as balance (Nobre, 2001). Reliable balance measurements are important in pediatrics as a way to justify intervention or to assess the results of

Several tests have been developed to assess the balance of individuals and establish parameters to identify those more susceptible to falling. However, these tests are even more geared toward seniors. Despite the abundance of measures that assess balance in seniors, this area has received less attention in Pediatrics.

One of the most used scales in the clinical setting to assess balance is the Berg Balance Scale (BBS), which was originally proposed to be for the assessment of static and dynamic balance in the elderly. The Berg scale showed extensive reliability in the geriatric population. The intraclass correlation coefficients (ICC) for reliability and test-retest as a whole were 0.98 and 0.99 , respectively. The ICC for individual test items ranged from 0.71 to 0.99 (Berg, Wooddauphinéee, \& Gayton, 1989).

From a pilot study of children with no changes in their development and who had low test-retest reliability in PBS, Franjoine, Gunther and Taylor (2003) it was observed that most of the children tested had difficulty in maintaining static postures. Therefore, changes were proposed and so the Pediatric Balance Scale (PBS) was developed. In its pediatric version, the items were reordered in a functional sequence, the time for the maintenance of static postures was also lowered, and suggested instructions and equipment were modified.

A few years later, the Brazilian version of PBS was published. It was written by Ries, Michaelsen, Soares, Monteiro and Allegretti (2012). They proposed the cultural adaptation and the assessment of the reliability of its version for use in children with cerebral palsy. The application range for visually impaired children is scarce. However, it unearthed a study of concurrent validation of the Pediatric Balance Scale with the stabilometer held in girls with visual impairment, aged 10-15 years old (Zyłka, Lach, \& Rutkowska, 2013).

In the reviewed literature, few publications were found about the application of the Pediatric procedures performed. Thus, arises the need for tools to identify the problems related to balance and allow the consolidation of the evaluation and for further therapeutic intervention.

Balance Scale in children with visual impairment. In general, studies of balance in children with this type of disability are based on small samples and have a greater focus on the differences between these children and the sighted (Bortolaia et al., 2003; Butz et al., 2015; Franjoine et al., 2003).

Therefore, the purpose of this study was to investigate the performance of children and adolescents with low vision on the Pediatric Balance Scale (PBS). The study also aimed to explore the relationship among age and PBS performance.

\section{METHOD}

It is about a descriptive-observational study of quantitative approach that is cross-sectional, because the researcher did not impose a treatment on the subjects, but used the information already available, and collected motor data in a determined time. The research was carried out at a reference center for children with low vision, in the city of Recife, Pernambuco, Brazil.

\section{Participants}

Forty-one children and adolescents with low vision that were registered at the reference center for visual impairment in the region, aged between 5 and 14 years participated in this study: $56.1 \%$ were male, $82.9 \%$ had moderate low vision, and $87.8 \%$ of the congenital type. Furthermore, $56.1 \%$ were under the care of other health professionals at the center in addition to the ophthalmologist. These professionals were physical therapists, psychologists and an educational psychologist.

For data analysis the sample was divided into three groups according to age, with the following mean age: Group I: $6-7$ years (mean $=6.22$, SD $=0.97$ ); Group II: $8-10$ years $($ mean $=9.37, \mathrm{SD}$ $=0.83$ ); and Group III: $11-14$ years (mean = $11.85, \mathrm{SD}=1.07)$. This division was based on the motor phases described by Gallahue, Ozmum and Goodway (2013) 
Subjects aged between five and 15 years (the age range that the scale is proposed review) and with low vision (moderate or severe) were included in the study and were diagnosed according to the criteria of the World Health Organization (2010) (Table 1), with at least one query for diagnosis ophthalmologist. Excluded subjects included those with heart and/or neurological based diseases (cerebral palsy, West syndrome) or hearing impairments; congenital malformation of physical order; severe cognitive deficit (no understanding of the simple orders of the test); or visual acuity to $3 / 60$ (0.05) blindness.

Table 1

Visual impairment classification, according to WHO (2010)

\begin{tabular}{lc}
\hline \multicolumn{1}{c}{ Classification } & Visual Field* \\
\hline No visual impairment & $1.0>0.3$ \\
Moderate visual impairment & $0.3>0.1$ \\
Severe visual impairment & $0.1>0.05$ \\
Blindness & $>0.05$ ou VF $<10^{\circ}$ \\
\hline
\end{tabular}

Note. ${ }^{*}$ In the best eye with the best optical correction.; $\mathrm{VF}=$ Visual Field; $\mathrm{WHO}=$ World Health Organization.

\section{Measures}

The instruments used for data collection were a socio-demographic questionnaire and the Pediatric Balance Scale (PBS).

Table 2

Items from the Brazilian version of the Pediatric Balance Scale adapted from Ries (2012)

\begin{tabular}{cl}
\hline & \multicolumn{1}{c}{ Pediatric Balance Scale } \\
\hline 1 & Seated position to standing position \\
\cline { 2 - 2 } 3 & Standing position to sitting position \\
\cline { 2 - 2 } 4 & Transfer \\
\cline { 2 - 2 } 5 & Standing without support \\
6 & Sitting without support \\
7 & Standing with eyes closed \\
8 & Standing with your feet together \\
9 & Standing with one foot in front \\
\cline { 2 - 2 } 10 & Standing on one foot \\
11 & Rotating 360 degrees \\
\cline { 2 - 2 } 12 & Tirning to look back \\
\cline { 2 - 2 } 13 & Placing up an object off the floor \\
\cline { 2 - 2 } 14 & Reaching forward foot on step / footrest \\
\hline
\end{tabular}

The PBS consists of 14 items, and for each item, the score is used from 0 to 4 , and the maximum score on the scale is 56 (Table 2). The higher the score, the better the balance. It was designed for children and adolescents aged five to 15 years and were developed to assess both their static and dynamic balance, including actions related to skills in the context of completing daily tasks. The test-retest and interrater reliability of the PBS were, respectively, 0.998 and 0.997, in school-aged children with mild to moderate motor impairment (Franjoine et al., 2003).

This scale was designed to require minimal use of specialized equipment. The items needed for its application were an adjustable seat; a chair with a backrest and armrests; a stopwatch; a footrest (15 centimeters high); a blackboard eraser; a tape measure and two molds of childsized feet.

\section{Procedures}

Initially, the recruitment of children and adolescents was conducted by analyzing the attendance registration in a reference center for this audience. Before starting the evaluations, there was a first contact moment with the mothers of the children to explain the purpose of the survey and the procedure. Soon after, the consent form was given out to get the authorization of the parent for the child's participation (according to CNS Resolution $466 / 2012$ ), as well as the informed assent document used for research subjects below 12 years.

Heights and weights were measured at the beginning and the socio-demographic questionnaire was filled in with mothers or guardians of the children and adolescents. The PBS was administered to each child/adolescent individually, using a protocol and scoring described by Franjoine et al. (2003).

Secondary data, such as type and degree of visual impairment were obtained through the registration of children at the reference center.

\section{Statistical analysis}

Data was tabulated and submitted for analysis by descriptive statistics using the EPI-info version 7 and SPSS version 20 Windows, for calculation of the central tendency (median) and dispersion (quartiles), as well as simple frequencies. 
The Kolmogorov-Smirnov test was used to test the normality of the data. After verifying that the data did not show a normal distribution, the Spearman rank correlation analyses were performed to determine the relationship between age of the children/adolescents and the PBS total test score.

For all statistical analysis the significance level of $5 \%$ was adopted, the alpha level set to 0.05 and also a $95 \%$ confidence interval.

Table 3

Anthropometric measures and score reached in the PBS, by age group. Recife, 2016

\begin{tabular}{|c|c|c|c|c|c|c|c|c|c|}
\hline \multirow[b]{2}{*}{$\begin{array}{c}\text { Age group } \\
\text { (age) }\end{array}$} & \multirow[b]{2}{*}{$\begin{array}{c}\text { Number of } \\
\text { subjects }\end{array}$} & \multicolumn{2}{|c|}{ Stature $(\mathrm{cm}) /$ Age } & \multicolumn{2}{|c|}{ Weight (Kg)/Age } & \multicolumn{2}{|c|}{ BMI/Age } & \multicolumn{2}{|c|}{ Score PBS } \\
\hline & & Median & $\begin{array}{c}\text { Quartile } \\
25 \\
\text { Quartile } \\
75\end{array}$ & Median & $\begin{array}{c}\text { Quartile } \\
25 \\
\text { Quartile } \\
75\end{array}$ & Median & $\begin{array}{c}\text { Quartile } \\
25 \\
\text { Quartile } \\
75\end{array}$ & Median & $\begin{array}{c}\text { Quartile } \\
25 \\
\text { Quartile } \\
75\end{array}$ \\
\hline $\begin{array}{c}\text { Group I } \\
\text { (5-7years) }\end{array}$ & 9 & 1.1 & $\begin{array}{l}0.8 \\
2.1 \\
\end{array}$ & 1.4 & $\begin{array}{l}-0.7 \\
2.1 \\
\end{array}$ & 0.8 & $\begin{array}{c}-0.2 \\
2.1 \\
\end{array}$ & 54 & $\begin{array}{l}50.0 \\
54.5 \\
\end{array}$ \\
\hline $\begin{array}{c}\text { Group II } \\
\text { (8-10years) }\end{array}$ & 19 & 0.5 & $\begin{array}{l}-0.1 \\
1.1 \\
\end{array}$ & 1.4 & $\begin{array}{c}-0.1 \\
1.9 \\
\end{array}$ & 1.6 & $\begin{array}{c}-0.7 \\
2.1 \\
\end{array}$ & 56 & $\begin{array}{l}55.0 \\
56.0\end{array}$ \\
\hline $\begin{array}{c}\text { Group III } \\
\text { (11-14years) }\end{array}$ & 13 & -0.2 & $\begin{array}{l}-0.7 \\
0.3\end{array}$ & - & - & 0.9 & $\begin{array}{c}-0.1 \\
2.0\end{array}$ & 56 & $\begin{array}{l}55.5 \\
56.0\end{array}$ \\
\hline
\end{tabular}

The Spearman correlation test showed a correlation of 0.52 with a confidence interval (95\%) of 0.24 to 0.74 , between the score achieved in the PBS and the age of the children and adolescents.

The children in age group I ( 5 to 7 years old) have a higher variance in the scores achieved on the PBS. In the group of 8 to 10 -year-old, $57.9 \%$ achieved the maximum score, $31.5 \%$ still scored 55 points and the remaining $(10.5 \%)$ reached 53 points. In the age group between 11 and 14 years, $76.9 \%$ achieved the maximum score (56) and only two individuals scored 55 points and one scored 53 and $53.6 \%$ of all participants reached maximum score of 56 points in the PBS.

\section{RESULTS}

All the subjects studied in non-specialized schools for disabled children, and only one reported physical activity (swimming), outside of the school curriculum, at a frequency of twice a week. The diagnosis of the most common causes of low vision was congenital cataracts and nystagmus, followed by high myopia e toxoplasmosis. Medians and percentiles of anthropometric measurements and score achieved on the scale (PBS) by age group, are shown in Table 3. adolescents on the scale, it was found that in six of the 14 total items the PBS maximum score was achieved by all the children and adolescents: 4 (Standing unsupported), 5 (Sitting unsupported) 6 (Standing with eyes closed), 7 (Standing with feet together), 10 (Turning 360॰) and 12 (Retrieving objects off the floor). The frequency of the score achieved on each task of the PBS by age group is shown in Table 4 .

The items where the children had greater difficulty were those in which you need to lower the base of support (item 8 and 9) or that a center of gravity shift is necessary (item 14).
Regarding the performance of children and 
Table 4

Frequency of the score reached in each item of the PBS. Recife. 2016

\begin{tabular}{|c|c|c|c|c|c|c|}
\hline \multirow{2}{*}{ Item from EEP } & \multirow{2}{*}{$\begin{array}{c}\text { Age group } \\
\text { (years) }\end{array}$} & \multicolumn{5}{|c|}{ Points score } \\
\hline & & 4 & 3 & 2 & 1 & 0 \\
\hline \multirow{3}{*}{1 Seated position for standing position } & $5-7$ & $95.12 \%$ & $4.88 \%$ & $\ldots$ & $\ldots$ & $\ldots$ \\
\hline & $8-10$ & $100 \%$ & $\ldots$ & $\ldots$ & $\ldots$ & $\ldots$ \\
\hline & $11-14$ & $100 \%$ & $\ldots$ & $\ldots$ & $\ldots$ & $\ldots$ \\
\hline \multirow{3}{*}{2 Standing position for sitting position } & $5-7$ & $95.12 \%$ & $4.88 \%$ & $\ldots$ & $\ldots$ & $\ldots$ \\
\hline & $8-10$ & $100 \%$ & $\ldots$ & $\ldots$ & $\ldots$ & $\ldots$ \\
\hline & $11-14$ & $100 \%$ & $\ldots$ & $\ldots$ & $\ldots$ & $\ldots$ \\
\hline \multirow{3}{*}{3 Transfer } & $5-7$ & $90.24 \%$ & $9.76 \%$ & $\ldots$ & $\ldots$ & $\ldots$ \\
\hline & $8-10$ & $100 \%$ & $\ldots$ & $\ldots$ & $\ldots$ & $\ldots$ \\
\hline & $11-14$ & $100 \%$ & $\ldots$ & $\ldots$ & $\ldots$ & $\ldots$ \\
\hline \multirow{3}{*}{4 Standing without support } & $5-7$ & $100 \%$ & $\ldots$ & $\ldots$ & $\ldots$ & $\ldots$ \\
\hline & $8-10$ & $100 \%$ & $\ldots$ & $\ldots$ & $\ldots$ & $\ldots$ \\
\hline & $11-14$ & $100 \%$ & $\ldots$ & $\ldots$ & $\ldots$ & $\ldots$ \\
\hline \multirow{3}{*}{5 Sitting without support } & $5-7$ & $100 \%$ & $\ldots$ & $\ldots$ & $\ldots$ & $\ldots$ \\
\hline & $8-10$ & $100 \%$ & $\ldots$ & $\ldots$ & $\ldots$ & $\ldots$ \\
\hline & $11-14$ & $100 \%$ & $\ldots$ & $\ldots$ & $\ldots$ & $\ldots$ \\
\hline \multirow{3}{*}{6 Standing with eyes closed } & $5-7$ & $100 \%$ & $\ldots$ & $\ldots$ & $\ldots$ & $\ldots$ \\
\hline & $8-10$ & $100 \%$ & $\ldots$ & $\ldots$ & $\ldots$ & $\ldots$ \\
\hline & $11-14$ & $100 \%$ & $\ldots$ & $\ldots$ & $\ldots$ & $\ldots$ \\
\hline \multirow{3}{*}{7 Standing with your feet together } & $5-7$ & $100 \%$ & $\ldots$ & $\ldots$ & $\ldots$ & $\ldots$ \\
\hline & $8-10$ & $100 \%$ & $\ldots$ & $\ldots$ & $\ldots$ & $\ldots$ \\
\hline & $11-14$ & $100 \%$ & $\ldots$ & $\ldots$ & $\ldots$ & $\ldots$ \\
\hline \multirow{3}{*}{8 Standing with one foot in front } & $5-7$ & $87.8 \%$ & $9.76 \%$ & $\ldots$ & $2.44 \%$ & $\ldots$ \\
\hline & $8-10$ & $95.12 \%$ & $4.88 \%$ & $\ldots$ & $\ldots$ & $\ldots$ \\
\hline & $11-14$ & $97.56 \%$ & $2.44 \%$ & $\ldots$ & $\ldots$ & $\ldots$ \\
\hline \multirow{3}{*}{9 Under one foot only } & $5-7$ & $82.92 \%$ & $9.76 \%$ & $2.44 \%$ & $4.88 \%$ & $\ldots$ \\
\hline & $8-10$ & $92.68 \%$ & $2.44 \%$ & $2.44 \%$ & $2.44 \%$ & $\ldots$ \\
\hline & $11-14$ & $100 \%$ & $\ldots$ & $\ldots$ & $\ldots$ & $\ldots$ \\
\hline \multirow{3}{*}{10 Rotating 360 degrees } & $5-7$ & $100 \%$ & $\ldots$ & $\ldots$ & $\ldots$ & $\ldots$ \\
\hline & $8-10$ & $100 \%$ & $\ldots$ & $\ldots$ & $\ldots$ & $\ldots$ \\
\hline & $11-14$ & $100 \%$ & $\ldots$ & $\ldots$ & $\ldots$ & $\ldots$ \\
\hline \multirow{3}{*}{11 Turning to look back } & $5-7$ & $97.56 \%$ & $2.44 \%$ & $\ldots$ & $\ldots$ & $\ldots$ \\
\hline & $8-10$ & $97.56 \%$ & $2.44 \%$ & $\ldots$ & $\ldots$ & $\ldots$ \\
\hline & $11-14$ & $100 \%$ & $\ldots$ & $\ldots$ & $\ldots$ & $\ldots$ \\
\hline \multirow{3}{*}{12 Catching objects } & $5-7$ & $100 \%$ & $\ldots$ & $\ldots$ & $\ldots$ & $\ldots$ \\
\hline & $8-10$ & $100 \%$ & $\ldots$ & $\ldots$ & $\ldots$ & $\ldots$ \\
\hline & $11-14$ & $100 \%$ & $\ldots$ & $\ldots$ & $\ldots$ & $\ldots$ \\
\hline \multirow{3}{*}{13 Placing alternate feet on the step } & $5-7$ & $97.56 \%$ & $2.44 \%$ & $\ldots$ & $\ldots$ & $\ldots$ \\
\hline & $8-10$ & $100 \%$ & $\ldots$ & $\ldots$ & $\ldots$ & ... \\
\hline & $11-14$ & $100 \%$ & $\ldots$ & $\ldots$ & $\ldots$ & $\ldots$ \\
\hline \multirow{3}{*}{14 Reaching the front } & $5-7$ & $90.24 \%$ & $7.32 \%$ & $\ldots$ & $2.44 \%$ & $\ldots$ \\
\hline & $8-10$ & $92.68 \%$ & $7.32 \%$ & $\ldots$ & $\ldots$ & $\ldots$ \\
\hline & $11-14$ & $100 \%$ & $\ldots$ & $\ldots$ & $\ldots$ & $\ldots$ \\
\hline
\end{tabular}

\section{DISCUSSION}

The score achieved in the PBS had a significant correlation with age up to a point, reaching ceiling effect on various items.

In previous studies, the balance ability of children and adolescents with visual impairments were compared to others without disabilities. The results showed that the children and adolescents with visual impairment present a worse performance level than the sighted (Aydog et al.,
2006; Houwen, Visscher, Lemmink, \& Hartman, 2008).

Citing Alves, Sousa, and Gardon Gagliardo (2014), the neuromotor development in children with visual impairments can be equal to that of a child without disabilities. The difference between children with and without visual impairments in development would be the slowest pace of acquisitions. However, these deficits were not analyzed in the context of daily activities, as 
reported by Zylka et al. (2013). Therefore, the difference compared with the non-disabled groups may not imply that this discrepancy affects the daily functioning of children and adolescents with disabilities.

Greater variances in the PBS score occurred in children between five and seven years old. However, the variability of performance was lower in older age groups, corroborating with Franjoine et al. (2003) which found that the variability of performance was lower in older age groups. Progressively higher scores were more pronounced between the ages of two and five years and were more modest between the ages of five and seven years in this same study.

The PBS showed a considerable ceiling effect, where $53.6 \%$ of children and adolescents achieved the maximum score on the scale. Unlike the results obtained in the study Zylka et al. (2013), conducted with 26 girls with visual impairment, both low vision and blindness, between 10 and 15 years old, where the mean PBS score varied between 47 and 56 , but only $11.5 \%$ achieved the maximum score on the scale. Importantly, only two of those girls had low vision, and the others had varying degrees of blindness.

Butz et al. (2015) evaluated 160 children without visual impairments, between five and 12 years and also noted that there was a positive correlation between score reached and age between five and seven years. The children from eight years old achieved the same points value in PBS (56 points), reaching the ceiling effect. Abraham et al (2009) in their study with sighted children found that they had achieved the maximum score up to nine years old. A similar result was confirmed in the study Franjoine et al. (2003) with 643 children without visual impairment and developing typically. There were $69.1 \%$ children over seven years old with a maximum score and $95 \%$ of the remaining achieved 53 points or more.

In the present study, in the group of eight to 10-year-old, 57.9\% achieved the highest score, the rest reached 53 points or more, and in the age group between 11 and 14 years, only three individuals scored 53 points or more. Comparing with the literature cited above, children and adolescents with low vision seem to resemble more the children without visual impairment in their performance in the PBS than children with more severe visual impairment.

Regarding the performance of children in each individual item of the scale it was found that six items were carried out with maximum score for all children and adolescents. Thus, children and adolescents with low vision in this study did not present difficulties in activities like; to sit without support, stand without support, with eyes open or closed, for activities of transfer or bending down to pick something up. The items that the children and adolescents had more difficulty in completing were those that had to include decreasing the support base (8 - Standing with one foot in front; 9 - Standing on one foot) or in gravity center displacement (14 - Reaching forward with outstretched arm). Results of previous studies indicated that girls with visual impairment have greater difficulty in the same items. The greatest difficulties in maintaining balance appeared in a single-limb stance; $88.5 \%$ of participants $(n=23)$ were not able to hold the position for 10 seconds or more and 15 (57.7\%) of the subjects demonstrated difficulty in reaching forward with an outstretched arm (Zyłka et al., 2013).

To identify this deficit in individual items, using a scale based on daily tasks is important, to propose a more targeted intervention for everyday situations, when visually impaired people are faced with an environment that is constantly changing.

The results show a moderate correlation between the final score of the PBS and the age of the children and adolescents evaluated, the same was observed in the study Butz, Sweeney, Roberts and Rauh (2015). This happens because the PBS scores do not follow a normal distribution pattern, especially in the older age groups in which most children/adolescents reached maximum score, or very close to the maximum in the test.

Some limitations should be taken into account in interpreting the results of this study. One limitation is the small sample size, which is 
because of the low incidence of blindness and low vision among children and adolescents. However, results should be interpreted with caution, therefore the sample may not be representative of children and adolescents with low vision. In this condition, the results obtained here cannot be extrapolated to the general population, but, nevertheless, they matter when you want to know what is necessary for measures to be adopted, which is the primary objective of this study. Still, before the scale is recommended for use in screening, planning and evaluation of the effectiveness of interventions, other psychometric properties of the PBS in this population need to be examined.

Another limitation was the use of children and adolescents enrolled in a reference center for this type of disability, what can happen is a selection bias, that these subjects may have been further stimulated. However, taking into account the study sought children and adolescents with severe degrees of low vision; they were more easily found in reference centers.

For future studies, the report suggests that the search for children and adolescents, who are part of stimulation programs in centers and others that have not undergone any kind of stimulation or specialized monitoring, is necessary to make comparisons. Aswell as a greater and more controlled sample. Another suggestion would be to compare children and adolescents with low vision and total blindness.

\section{CONCLUSION}

The Pediatric Balance Scale showed up as a functional balance-screening tool appropriate for children and adolescents with low vision, being more appropriate for children ages five to seven years old. In children older than eight years old the ceiling effect occurred. Children and adolescents with low vision do not show difficulties in tasks of sitting without support, standing without support (with open or closed eyes), transfers, turning $360^{\circ}$ or taking objects off the floor. However, they showed more difficulty where it was necessary to reduce their support base or with gravity center displacement. The present findings need to be confirmed by further studies.

\begin{tabular}{l}
\hline Acknowledgments: \\
The authors thank all children and adolescents and \\
their families who participated in this study.
\end{tabular}

Conflict of interests:

Nothing to declare.

\begin{tabular}{l}
\hline Funding: \\
Coordination of Improvement of Higher Education \\
Personnel - CAPES
\end{tabular}

\section{REFERENCES}

Abraham, A., \& Ravindra, S. (2006). Assessment of age or attainment of balance in children using Pediatric Balance Scale (PBS). Pediatric Oncall. (suppl 1), 3. http://www.pediatriconcall.com/fordoctor/confe rence abstracts/pediatric

Alves, P. V., Fraga de Sousa, G. A., Gardon Gagliardo, H. G. R. (2014). Habilidades funcionais na criança com cegueira congênita: um estudo de caso. Revista de Terapia Ocupacional da Universidade de São Paulo, 25(3), 248-254. doi: 10.11606

Andrade, C. D. A., Gois, M. L. C. C., Victorio Vitor, L. G., Raio, J. C., Zechim, F. C., Silva, R. A., \& Fujisawa, D. S. (2012). Equilíbrio em crianças com deficiência visual em fase escolar. ConScientiae Saúde, 11 (4), 625-634. doi: 10.5585

Aydog, E., Aydog, S. T., Cakci, A., \& Doral, M. N. (2006). Dynamic postural stability in blind athletes using the biodex stability system. International Journal of Sports Medicine, 27, 415-418. doi: 10.6061

Berg, K., Wood-dauphinéee, S., \& Gayton, D. (1989). Mensuring balance in the elderly: preliminary development of an instrument. Physiotherapy Canada, 41(6), 304-311. doi: $10.3138 /$ ptc. 41.6 .304

Bortolaia, A. P., Barela, A. M. F., \& Barela, J. A. (2003). Controle postural em crianças portadoras de deficiência visual nas faixas etárias entre 3 e 11 anos. Motriz, 9(2), 75-82.

Butz, S. M., Sweeney, J. K., Roberts, P. L., \& Rauh, M. J. (2015). Relationships Among Age, Gender, Anthropometric Characteristics, and Dynamic Balance in Children 5 to 12 Years Old. Pediatric Physical Therapy, 27(2), 126-133. doi: 10.1097/PEP.0000000000000128

Eckert, M. (1993). Desenvolvimento motor ( $3^{\mathrm{a}}$ ed.). São Paulo: Editora Manole.

Franjoine, M. R., Gunther, J. S., \& Taylor, M. J. (2003). Pediatric Balance Scale: a modified version of the 
Berg Balance Scale for the school-age child with mild to moderate motor impairment. Pediatric Physical Therapy, 15(2), 114-128. doi: 10.1097/01.PEP.0000068117.48023.18

Franjoine, M. R., Darr, N., Held, S. L., Kott, K., Young, B. L. (2010). The Performance of Children Developing Typically on the Pediatric Balance Scale. Pediatric Physical Therapy, 22 (4), 350-359. doi: 10.1097/PEP.0b013e3181f9d5eb

Gallahue, D. L., Ozmun, J. C., \& Goodway, J. D. (2013). Compreendendo o desenvolvimento motor: bebês, crianças, adolescentes e adultos. ( $7^{\mathrm{a}}$ ed.). São Paulo: Editora McGraw-Hill.

Houwen, S., Visscher, C., Lemmink, K. A. P. M., \& Hartman, E. (2008). Motor skill performance of school-age children with visual impairments. Developmental Medicine e Child Neurology, 50, 139145. doi: 10.1111/j.1469-8749.2007.02016

Malta, J., Endriss, D., Rache, D. S., Moura, T., \& Ventura, L. (2006). Desempenho funcional de crianças com deficiência visual, atendidas no Departamento de Estimulação Visual da Fundação Altino Ventura. Arquivos Brasileiros de Oftalmologia, 69(4), 571-574. doi: 10.1590/S0004-27492006000400021

Matos, M. R., Matos, C. P. G., \& Oliveira, C. S. (2010). Equilíbrio estático da criança com baixa visão por meio de parâmetros estabilométricos. Fisioterapia e Movimento, 23(3), 361-369. doi: $10.1590 /$ S0103-51502010000300003
Navarro, A. S., Fukujima, M. M., Fontes, S. V., Matas, S. L. A., \& Prado, G. F. (2004). Coordenação motora e equilíbrio não são totalmente desenvolvidos em crianças cegas com 7 anos de idade. Arquivos de Neuropsiquiatria, 62(3), 654657.

Nobre, M. I. R. S., \& Gardon Gagliardo, H. G. R. (2001). Intervenção Precoce na Criança com Baixa Visão. Revista Neurociências, 9(1), 16-19.

Ries, L. G. K., Michaelsen, S. M., Soares, P. S. A., Monteiro, V. C., \& Allegretti, K. M. G. (2012). Cross-cultural adaptation and reliability analysis of the Brazilian version of Pediatric Balance Scale (PBS). Revista Brasileira de Fisioterapia, 16 (3), 20515. doi: 10.1590/S1413-35552012005000026

Soares, F. A., Silva, T. R., Gomes, D. P., \& Pereira, E. T. (2012). A contribuição da estimulação psicomotora para o processo de independência do deficiente visual. Motricidade, 8(4), 16-25. doi: 10.6063

World Health Organization. International Classification of Diseases, version 2010. http://apps.who.int/classifications/icd10/brows e/2010/ en\#/H54. Accessed July 20, 2014.

Zyłka, J., Lach, U., \& Rutkowska, I. (2013). Functional balance assessment with pediatric balance scale in girls with visual impairment. Pediatric Physical Therapy, 25(4), 460-466. doi: 10.1097/PEP.0b013e31829ddbc8 